\title{
ESTRATÉGIAS DE SEGMENTAÇÃO E DE TRADUÇÃO UTILIZADAS POR TRADUTORES HUMANOS: DA COMBINAÇÃO DE ORAÇÕES À ESTRUTURA RETÓRICA
}

\author{
SEGMENTATION AND TRANSLATION STRATEGIES USED BY HUMAN \\ TRANSLATORS: FROM CLAUSE COMBINING TO RHETORICAL STRUCTURE
}

\author{
Juliano Desiderato Antonio| Lattes | jdantonio@uem.br \\ Universidade Estadual de Maringá
}
Liliam Cristina Marins | Lattes | liliamchris@hotmail.com Universidade Estadual de Maringá

Luiza Prevedel Pereira | Lattes | luizaprevedel@hotmail.com Universidade Estadual de Maringá

Resumo: Este trabalho tem como objetivo investigar estratégias de segmentação e de tradução utilizadas por tradutores humanos. O nível em que a análise é realizada é o da estrutura textual, por meio da Rhetorical Structure Theory (RST). O córpus do trabalho é formado por treze sinopses de filmes em inglês e suas versões do inglês para o português feitas por formandos do curso de Tradução. Na análise, investiga-se a frequência de concordância entre a segmentação dos textos em unidades discursivas elementares e comparam-se a estrutura retórica do texto fonte e a estrutura retórica da tradução. A análise permitiu identificar cinco diferentes estratégias utilizadas pelos tradutores e duas inadequações no processo de versão dos textos do inglês para o português. Os resultados mostram que os tradutores humanos, diferentemente dos tradutores mecânicos, promovem transformações inevitáveis nas estruturas linguísticas do texto traduzido, as quais são fruto da relação desse sujeito tanto com a língua estrangeira quanto com sua própria língua materna. Justamente por ser humana, ela se distancia de um ideal de perfeição, bem como de uma possível busca por equivalências estruturais entre línguas que são, a rigor, diferentes.

Palavras-chave: Rhetorical Structure Theory. Tradução. Segmentação. 
Abstract: This paper aims at investigating the segmentation and translation strategies used by human translators. The analysis is performed at the textual structure following the Rhetorical Structure Theory (RST). The corpus consists of thirteen synopses of films and their English-Portuguese versions made by undergraduate students of Translation. In the analysis, we investigated the frequency of agreement between text segmentation into elementary discourse units and compared the rhetorical structure of both the source text and the translations. The analysis allowed us to identify five different strategies and two inadequacies used by translators in the process of translating texts from English to Portuguese. The results show that human translators, unlike mechanical translators, promote inevitable transformations in the linguistic structures of the translated texts, which are the result of the translators' relationship with both the foreign language and their first language. Because it is human, it distances itself from an ideal of perfection, as well as from a possible search for structural equivalences between languages that are, strictly speaking, different.

Keywords: Rhetorical Structure Theory. Translation. Segmentation.

\section{Considerações iniciais}

A língua inglesa ocupa, em uma prática tradutória localizada em um cenário de globalização, um lugar de visibilidade, atravessando os sujeitos em várias instâncias, inclusive identitárias, no "ser" entre línguas, e permitindo mobilidade e trocas transculturais (CORACINI, 2005). É a língua utilizada no comércio global, na diplomacia internacional, no controle de tráfego aéreo, em publicações científicas, e, no dia a dia, é a língua mais comumente utilizada na internet e também por turistas que necessitam comunicar-se com habitantes dos locais que visitam quando as línguas dos visitantes e dos visitados não é comum. Diante disso, há uma enorme demanda pela tradução de textos de e para o inglês, motivo pelo qual o objetivo deste trabalho é investigar estratégias de segmentação e de tradução utilizadas por tradutores humanos, desde a combinação de orações até a estrutura retórica, de textos vertidos do inglês para o português.

A tradução humana, enquanto prática sociodiscursiva, é sempre empreendida por um sujeito constituído ideológico-político e culturalmente, o que é responsável por distanciar essa prática de um ideal de neutralidade, equivalência e fidelidade linguística a um original. Ao realizar determinada escolha tradutória em detrimento de outra, o tradutor está, inevitavelmente, marcando-se nesse movimento discursivo (ARROJO, 1996). No entanto, isso não significa manipulação ou usurpação da mensagem original, mas uma característica intrínseca (e desejável) do fazer tradutório humano em todo e qualquer 
gênero discursivo; ou seja, não é um movimento interpretativo exclusivo da tradução de textos que circulam na esfera artística. Além de romper com a linha abissal que separa a tradução artística (tradicionalmente vinculada à maior liberdade de escolhas) da tradução comunicativa (tradicionalmente concebida como aquela que apresenta menor leque de possibilidades tradutórias), o reconhecimento da tradução enquanto materialização das escolhas de um tradutor também desconstrói a ideia de língua como um sistema engessado, estático e imutável - herdada de uma vertente mais prescritiva dos estudos da tradução - em direção a uma concepção mais dinâmica, fluida e funcionalista da linguagem em seus mais diversos usos e práticas individuais e sociais.

Esse olhar mais funcional da prática tradutória, que se estabeleceu em especial na escola fucionalista alemã com Reiss, Vermeer e Nord, consolida-se nos estudos da tradução enquanto questionamento dos preceitos tradicionalmente vinculados a uma vertente mais prescritivista, que via na tradução um transporte cuidadoso do sentido contido nas palavras do original para seu equivalente no destino final, sem provocar danos à sua integridade (RODRIGUES, 2000, p. 169). Em contraposição, a vertente funcional questiona a dependência conceitual da tradução a uma noção de equivalência (seja no nível sintático ou no semântico) e o processo de tradução passa a ser norteado pela "fidelidade" ao objetivo tradutório, de forma a contemplar também o leitor e o contexto de chegada (não apenas o autor e o contexto de produção):

\footnotetext{
Em outras palavras, ser funcionalista em tradução significa ter como foco principal a função (ou funções) inerente(s) aos textos e às traduções, visto que se pressupõe que todo texto, traduzido ou não, detém um propósito específico, uma intenção sustentada na relação presumida entre produtor e leitor(es) final (COSTA; ZILPSER; POLCHLOPEK, 2012, p. 26).
}

Reconhecer a posição entre-lugares da tradução significa pensar nessa prática como fronteiriça (não é nem o espelho do original, nem mesmo um texto completamente novo), além de suscitar a reflexão de que o mundo não pode ser lido por meio de uma língua única, mesmo que esta tenha uma posição hegemônica (GENTZLER, 2009), como o inglês. Ou seja, a tradução é necessária e deve ser considerada como uma ponte entre línguas e culturas diferentes.

Ao partir dessa concepção de tradução nos entre-lugares, busca-se analisar, neste texto, as estratégias de tradutores em formação de um curso de Tradução de uma universidade paranaense para a versão de treze sinopses de filmes do inglês para o português. Um anotador com experiência em RST segmentou e anotou as relações que caracterizam os textos de partida e os textos traduzidos a fim de identificar as estratégias utilizadas 
pelos tradutores. O nível em que a análise se realiza é o da estrutura textual, por meio da Rhetorical Structure Theory (RST), uma teoria descritiva que tem por objeto o estudo da organização dos textos, caracterizando as relações que se estabelecem entre as partes do texto (MANN; HOMPSON, 1988). O estudo de estratégias de tradução por meio da RST foi inicialmente proposto por Da Cunha e Iruskieta (2010) e mostrou-se muito produtivo para a explicação de diferenças na estrutura retórica dos textos vertidos motivadas pela escolha de diferentes estratégias por parte dos tradutores.

\section{Fundamentação teórica}

De acordo com Matthiessen (2005), a RST surgiu das pesquisas relacionadas ao estudo da organização textual tendo em vista a geração automática de textos. A RST tem como principal pressuposto o fato de que as orações de um texto veiculam mais do que apenas conteúdo proposicional explícito. Da combinação entre as orações e as partes de um texto surgem proposições implícitas, as chamadas proposições relacionais, que recebem outros rótulos como "relações retóricas", "relações discursivas", "relações de coerência” (TABOADA, 2009, p. 127).

Uma lista de 32 relações pode ser encontrada no website da teoria (www.sfu.ca/ rst). No entanto, como apontam Mann e Thompson (1988), essa lista não representa um rol fechado, e mais relações podem ser acrescentadas. Em termos de organização, as relações podem ser de dois tipos: a) núcleo-satélite, nas quais uma porção do texto (satélite) é ancilar da outra (núcleo), como na figura 1, em que um arco vai da porção que serve de subsídio para a porção que funciona como núcleo; b) multinucleares, nas quais uma porção do texto não é ancilar da outra, sendo cada porção um núcleo distinto, como na figura 2.

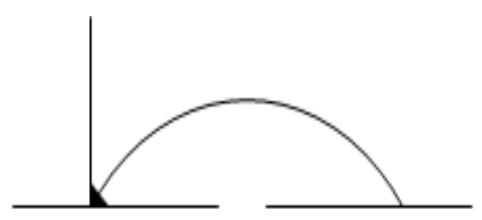

Figura 1 - Relação núcleo-satélite (MANN E THOMPSON, 1988, p. 247)

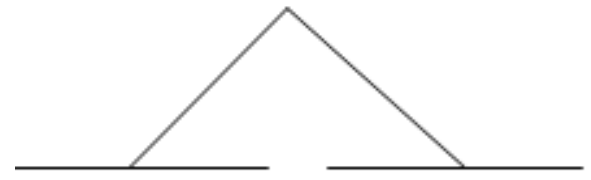

Figura 2 - Relação multinuclear (MANN E THOMPSON, 1988, p. 247)

A estrutura retórica de um texto é representada por um diagrama arbóreo e é definida pelas redes de relações que se estabelecem entre porções de texto sucessivamente maiores. Segundo Mann e Thompson (1988), a estrutura retórica é funcional, pois leva 
em conta como o texto produz um efeito sobre o enunciatário, ou seja, toma como base as funções que as porções do texto assumem para que o texto atinja o objetivo global para o qual foi produzido. Na figura 3, pode-se observar a estrutura retórica de uma sinopse do córpus deste trabalho.

A unidade central da sinopse, núcleo para o qual todos os satélites apontam, é a unidade 9 (STEDE, 2008). Em outras palavras, a porção de texto formada pelas unidades de 1 a 8 estabelece a relação "motivation" com a unidade 9, ou seja, tem a função de motivar o leitor a realizar a ação mencionada na unidade 9, a saber, "experienciar o filme”. As unidades de 1 a 4 formam uma porção de texto que funciona como satélite de "background" para a porção formada pelas unidades de 5 a 8, isto é, as unidades de 1 a 4 apresentam informações sem as quais ficaria difícil para o leitor compreender o conteúdo do núcleo. Entre as unidades 1 e 3 estabelece-se a relação "same unit", que é uma relação estrutural para representar, no diagrama, que a unidade 2 está intercalada entre essas duas unidades. A unidade 2 estabelece a relação "cause" com a unidade 3. Nessa relação, o evento presente no satélite causa o evento presente no núcleo. Na relação "elaboration", a unidade 4 (satélite) acrescenta informações adicionais ao conteúdo do núcleo. Na relação "circumstance", presente nas unidades 5 e 7, o satélite fornece a moldura na qual o conteúdo do núcleo deve ser interpretado. Por fim, entre as porções de texto formadas pelas unidades 5-6 e 7-8, estabelece-se a relação multinuclear "sequence", que apresenta eventos que se sucedem temporalmente.

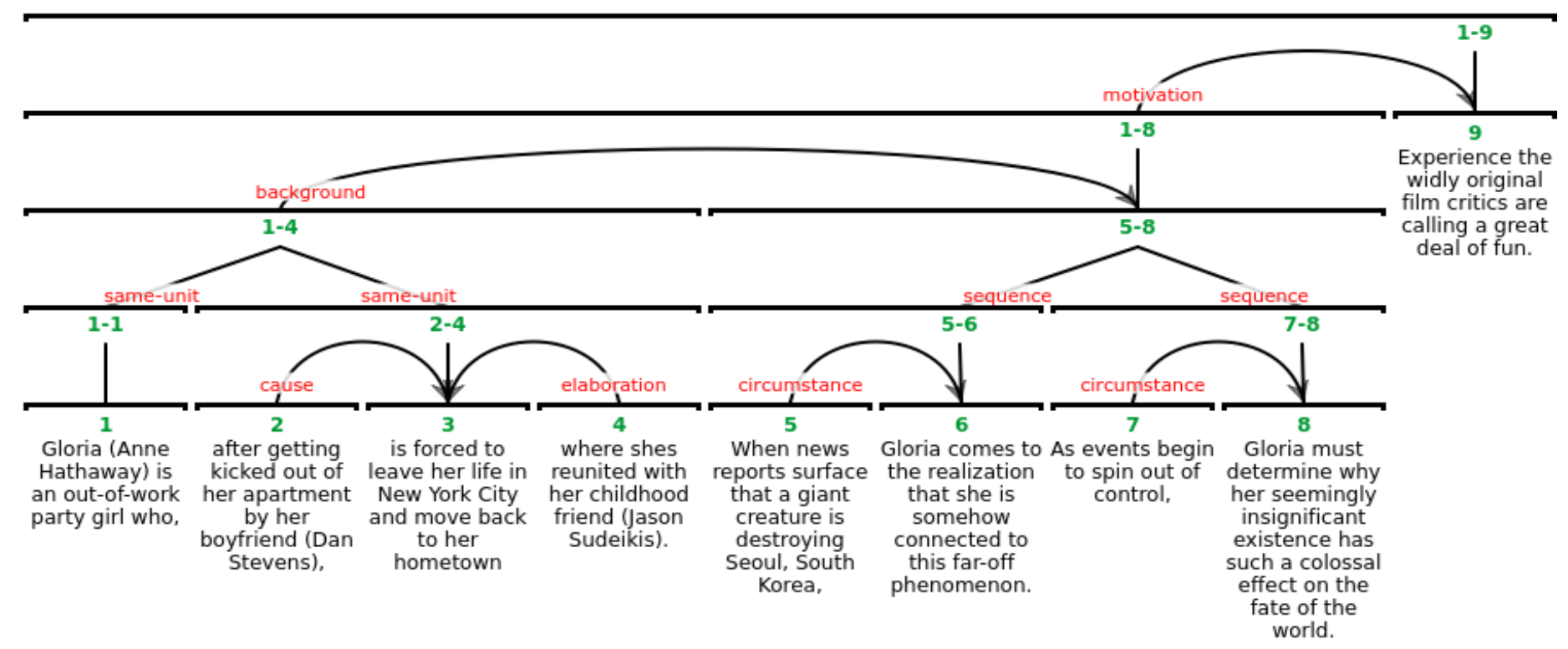

Figura 3 - Diagrama da estrutura retórica de uma sinopse do corpus (Fonte: os autores). 


\section{Metodologia}

As treze sinopses que compõem o córpus deste trabalho foram retiradas do serviço de streaming iTunes. Como se pode verificar na figura 4 a seguir, cada texto tem duas partes: Review e About the movie. Cada uma dessas partes foi analisada separadamente.

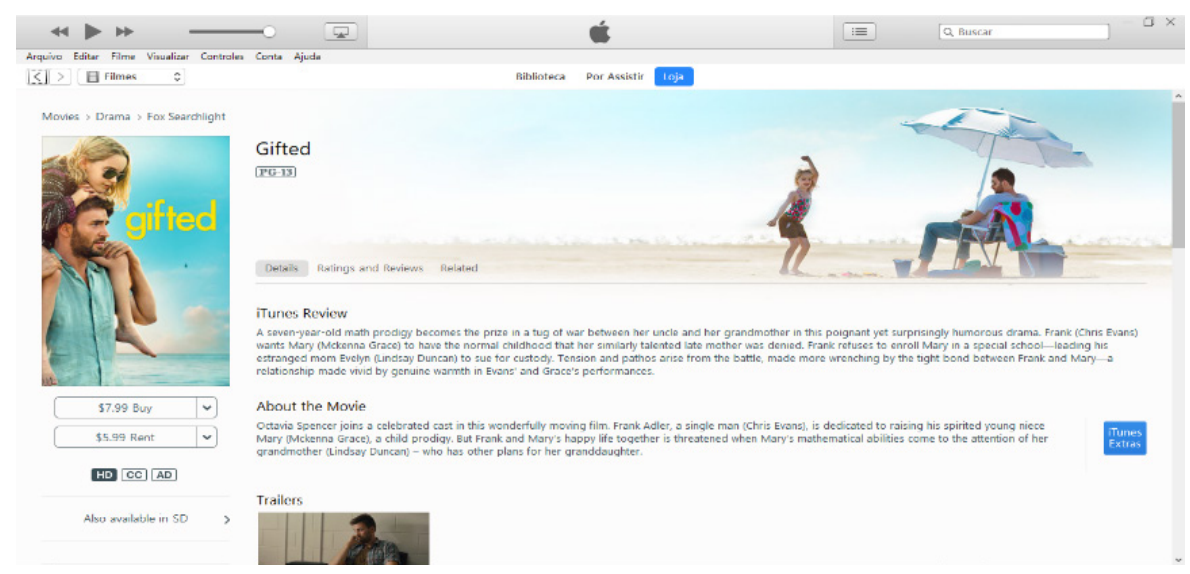

Figura 4 - Captura de tela do iTunes com uma das sinopses do córpus do trabalho (Fonte: itunes).

As sinopses originais bem como suas versões para o português, que já haviam sido vertidas em uma atividade do curso de Tradução, foram segmentadas em Elementary Discourse Units (EDUs) por anotadores com experiência em RST. As EDUs são blocos mínimos de construção de uma árvore discursiva (CARLSON; MARCU, 2001). Geralmente, as EDUs correspondem a orações, com exceção de orações completivas e de orações restritivas, que não estabelecem relações retóricas pelo fato de funcionarem como argumento da oração principal, no caso das completivas, ou como complicação de um tema, no caso das restritivas.

O passo seguinte foi verificar se houve diferenças na segmentação do texto traduzido em relação ao texto fonte motivadas pelas estratégias de tradução utilizadas pelos tradutores. Por fim, os anotadores criaram as árvores discursivas dos textos do córpus para verificação de diferenças na estrutura dos textos motivadas por diferenças nas estratégias de tradução.

\section{Análise}

A primeira verificação que se fez foi com relação ao número de EDUs por texto. Como é possível verificar na tabela 1 a seguir, houve diferença na quantidade de EDUs do texto traduzido em relação ao texto-fonte em 12 textos. 


\begin{tabular}{|c|c|c|c|}
\hline & & Texto-fonte & Texto traduzido \\
\hline \multirow{2}{*}{ Beauty and the Beast } & About the movie & 7 & 7 \\
\hline & Review & 5 & 9 \\
\hline \multirow{2}{*}{ Colossal } & About the movie & 9 & 9 \\
\hline & Review & 7 & 8 \\
\hline \multirow{2}{*}{ Free Fire } & About the movie & 6 & 6 \\
\hline & Review & 8 & 7 \\
\hline \multirow{2}{*}{ Ghost in the Shell } & About the movie & 13 & 9 \\
\hline & Review & 5 & 4 \\
\hline \multirow{2}{*}{ Gifted } & About the movie & 5 & 5 \\
\hline & Review & 7 & 5 \\
\hline \multirow{2}{*}{ Kong: Skull Island } & About the movie & 3 & 4 \\
\hline & Review & 7 & 7 \\
\hline \multirow{2}{*}{ La La Land } & About the movie & 5 & 4 \\
\hline & Review & 6 & 6 \\
\hline \multirow{2}{*}{ Night of the Living Dead } & About the movie & 3 & 3 \\
\hline & Review & 9 & 9 \\
\hline \multirow{2}{*}{ The Boss Baby } & About the movie & 3 & 3 \\
\hline & \begin{tabular}{|l|} 
Review \\
\end{tabular} & 9 & 9 \\
\hline \multirow{2}{*}{ The Circle } & About the movie & 5 & 5 \\
\hline & Review & 6 & 6 \\
\hline \multirow{2}{*}{ The Fate of the Furious } & About the movie & 8 & 10 \\
\hline & Review & 7 & 6 \\
\hline \multirow{2}{*}{ The Lost City of Z } & About the movie & 7 & 7 \\
\hline & Review & 7 & 5 \\
\hline \multirow{2}{*}{ The Zookeeper's Wife } & About the movie & 9 & 9 \\
\hline & Review & 8 & 7 \\
\hline
\end{tabular}

Tabela 1 - Quantidade de EDUs por texto

As diferenças apresentadas na tabela são decorrentes do emprego de cinco diferentes estratégias empregadas pelos tradutores e também de dois tipos de escolhas inadequadas na circulação do gênero em língua portuguesa. É possível observar que não há uma equivalência entre o número de EDUs na língua de partida e na língua de chegada, o que pode confirmar um processo significativo de reformulação linguística quando comparado a tradutores não humanos, por exemplo. Pensar na tradução nesse movimento é reconhecer que toda tradução é a materialização da relação de um sujeito com sua língua e com a língua do outro, o qual deixa marcas individuais não só semanticamente, mas também na imagem que esse sujeito (des)constrói de sua própria língua. Se o tradutor é, 
inevitavelmente, um leitor do texto de partida, não é possível aceitar a possibilidade desse leitor apenas decodificar o código escrito, já que esse ato "destituiria a língua de sua dinâmica transformadora e priva[ria] o texto de sua função de prática social comunicativa” (COSTA; ZILPSER; POLCHLOPEK, 2012, p. 26).

Em três sinopses (Beauty and the beast - review, The fate of the furious - review e The Zookeeper's wife - review), é possível observar as escolhas dos tradutores ao reconstruírem períodos inteiros e selecionarem as informações que serão traduzidas. No exemplo (01), retirado da sinopse do filme Beauty and the beast, o tradutor trouxe para o início do período da tradução (unidade 5) o tópico "destaque" do elenco. No texto de partida, o vocábulo inglês ("standout") está no final da EDU. Em 7, utilizou adjetivos em posição predicativa ("que é arrogante e vaidoso"), ao passo que, no texto de partida, os adjetivos são atributivos ("vain, arrogant war hero"). Em 9, utiliza o verbo "interpretar", ao passo que, no texto de partida, não se utiliza verbo. Com essa reconstrução textual, uma única EDU do texto fonte (unidade 5) se transformou em 5 EDUs, o que pode mostrar que as línguas não são sistemas que podem equivaler-se, principalmente quando se considera um caráter mais sintético da língua inglesa em relação à língua portuguesa. Por um olhar funcionalista, a noção de língua pautada pela arbitrariedade e pelo formalismo saussuriano, cujo desdobramento é o desejo de tradução equivalente e fiel, é rompida para dar lugar a uma concepção de língua (e de tradução) como ferramenta de comunicação cultural entre autor e leitor (COSTA; ZILPSER; POLCHLOPEK, 2012).

(01) 5 Luke Evans as the vain, arrogant war hero Gaston and Ewan McGregor as the debonair candelabra Lumière are standouts among the large, sleek cast.

5 Destaques entre o grande e funcional elenco são Luke Evans, 6 interpretando o herói de guerra Gaston,

7 que é arrogante e vaidoso,

8 e Ewan McGregor,

9 interpretando o charmoso candelabro Lumière.

Outra estratégia utilizada pelos tradutores foi a inclusão ou retirada de verbos em construções. Tal estratégia foi empregada em três sinopses: Colossal - review, Ghost in the shell - review, The boss baby - review, The fate of the furious - about the movie, The lost city of $Z$ - review. No exemplo (02), retirado da sinopse do filme The boss baby, o 
texto de partida apresenta uma construção comparativa com duas orações (EDUs 7 e 8). Na versão para o português, o verbo da segunda oração é suprimido pelo tradutor, motivo pelo qual o trecho correspondente à segunda oração do texto de partida não foi segmentado. Já na EDU 9 do texto de partida ocorre o contrário. Encontra-se, no texto em inglês, o adjetivo "enchanting". Na versão para o português, o tradutor optou por uma oração apositiva ("que encanta...”). A língua compreendida como prática social, noção que se opõe à ideia de um mero meio transparente de restituir sentidos, possibilita tal reorganização para que se atenda aos propósitos da tradução (deixar o texto mais familiar para leitores em língua portuguesa, por exemplo, considerando que um dos objetivos da vertente funcionalista é justamente atender o leitor final, seja do texto de partida ou do texto de chegada) e, ao mesmo tempo, se revele como esse tradutor, que é, primeiramente, um leitor do texto de partida, interage com sua língua mãe.

(02) 7 Sibling rivalry has never been so strange, 8 and it's rarely been as funny.

9 Baldwin is simply brilliant as an ambitious infant on a mission in this colorful film with an antic screwball style as enchanting to grownups as children.

7 Essa rixa entre irmãos nunca foi tão estranha, nem tão engraçada.

8 Baldwin é simplesmente brilhante no papel de uma criança ambiciosa em uma importante missão nesse filme super colorido, esquisito e excêntrico, 9 que encanta tanto as crianças como os adultos.

A mudança do arranjo da combinação de orações também foi um recurso utilizado pelos tradutores em quatro sinopses (Ghost in the shell - about the movie; Kong: Skull Island - about the movie; The lost city of $\mathrm{Z}$ - review; La la land - about the movie). No exemplo (03), retirado da sinopse do filme Kong: Skull Island, utiliza-se, no texto fonte, uma oração restritiva em 3 ("that reveals"), ao passo que, na versão para o português, o tradutor optou pelo gerúndio, favorecendo a leitura de resultado. A estratégia utilizada pelo tradutor resultou em uma EDU a mais no texto vertido para o português. Essa transformação estrutural da língua também pode mostrar um deslocamento desse tradutor em relação a um possível espelhamento da tradução em relação à língua de partida. 
(03) 3 Tom Hiddleston, Samuel L. Jackson, Brie Larson, John Goodman and John C. Reilly star in a thrilling and original adventure that reveals the untold story of how Kong became King.

3 Tom Hiddleston, Samuel L. Jackson, Brie Larson, John Goodman e John C. Reilly compõem uma aventura incrível, 4 revelando como Kong se tornou King.

Nas sinopses dos filmes Free fire - review; Ghost in the shell - about the movie; Gifted - review, uma estratégia utilizada pelos tradutores foi a mudança de classe de algumas palavras. No exemplo (04), retirado da sinopse do filme Ghost in the shell, no texto fonte utiliza-se uma forma verbal no gerúndio na EDU 3 ("Believing"), ao passo que, na versão para o português, o tradutor optou por uma forma participial que funciona como adjetivo ("Convencida"), motivo pelo qual a EDU 3 não foi segmentada em 2 EDUs. No texto-fonte, em 6, utiliza-se uma construção temporal com forma verbal ("While investigating"). Na versão para o português, também se utiliza uma construção temporal. No entanto, a forma verbal foi nominalizada pelo tradutor ("Durante a investigação"). Em ambos os casos, a mudança de classe altera a segmentação dos textos. Como as EDUs devem conter verbos, as opções do tradutor da sinopse exemplificada em (03) levaram à não-segmentação de duas EDUs, embora essas escolhas não representem “ônus” às construções de sentidos dentro da proposta de tradução e em relação ao gênero discursivo.

(04) 3 Believing she was rescued from near death, 4 Major (Johansson) becomes the first of her kind:

5 a human mind inside an artificial body designed to fight that war against cyber-crime.

6 While investigating a dangerous criminal, 7 Major makes a shocking discovery

3 Convencida de que foi salva de uma morte quase inescapável, Major (Johansson) torna-se a primeira de sua espécie:

4 uma mente humana dentro de um corpo artificial criada para combater crimes cibernéticos.

5 Durante a investigação de um criminoso altamente perigoso, Major faz uma descoberta chocante - 
As diferenças na segmentação são responsáveis por alterações na estrutura retórica da sinopse traduzida em relação à sinopse fonte. Nos diagramas das figuras 5 e 6, a primeira diferença pode ser observada nas EDUs 3 e 4. No texto vertido para o português, em função do uso do particípio "convencida" e da consequente não-segmentação da unidade 3, não se estabelece a relação "cause", como no texto fonte. O mesmo ocorre na EDU 6 do texto fonte, em que se utiliza a construção temporal "while investigating", sinalizando a relação "circumstance". No texto vertido para o português, a opção do tradutor por utilizar uma construção temporal com a nominalização do verbo "investigar" ("Durante a investigação") não permitiu a segmentação, de forma que a relação "circumstance" não foi estabelecida. Na EDU 10 do texto de partida, a construção "Unsure what to believe" sinaliza a relação "cause" com a porção de texto formada pelas unidades 11-13. Na versão para o português, o tradutor optou pela relação de concessão, sinalizada, na unidade 8 , pela expressão "mesmo sem”. As relações de causa e de concessão, bem como a relação de condição, situam-se, de acordo com Neves (2000), em um mesmo contínuo semântico. De acordo com a autora, há um extremo em que a relação de causa é afirmada (construções causais), um extremo em que o vínculo causal entre as orações é negado (construções concessivas) e um espaço intermediário em que a relação de causa entre as orações é hipotetizada (condicionais). Por fim, no texto-fonte, nas EDUs 12 e 13 há duas orações de propósito relacionadas parataticamente e que funcionam como satélite da oração nuclear em 11. Já na tradução (EDU 9), a segunda oração é tomada como escopo da oração nuclear, juntamente com a primeira oração.

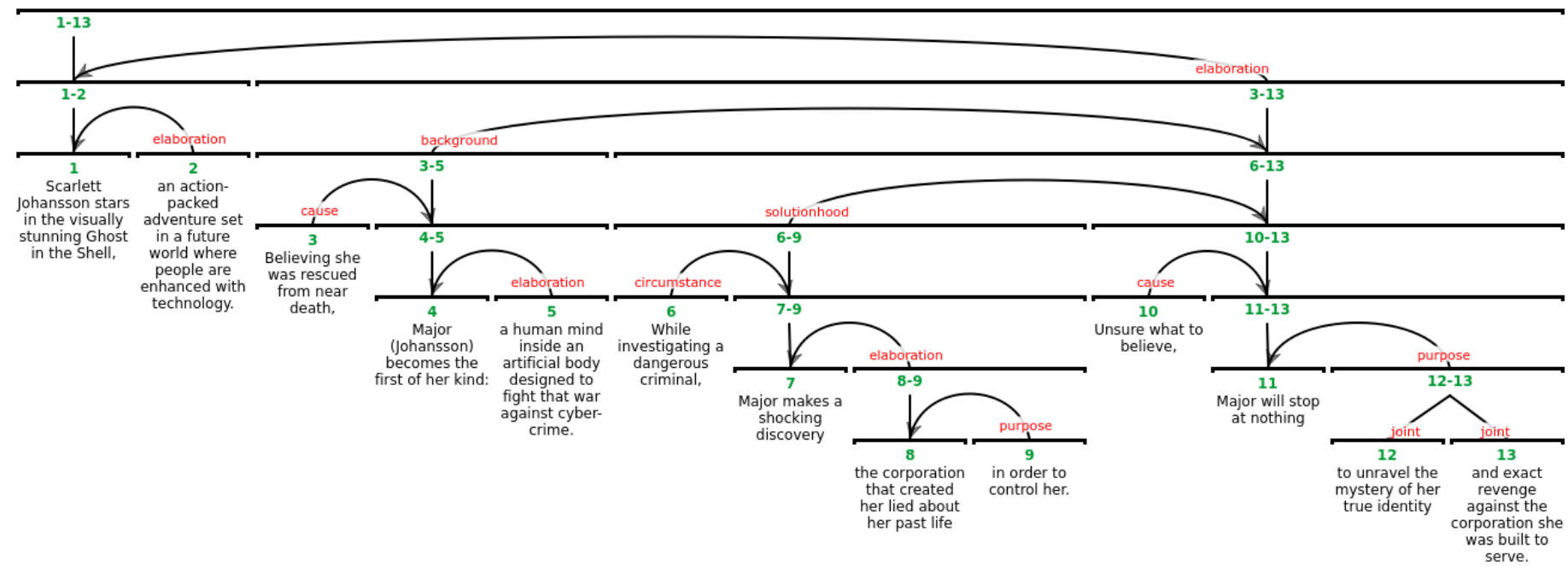

Figura 5 - Diagrama da estrutura retórica de uma sinopse-fonte (Fonte: os autores). 


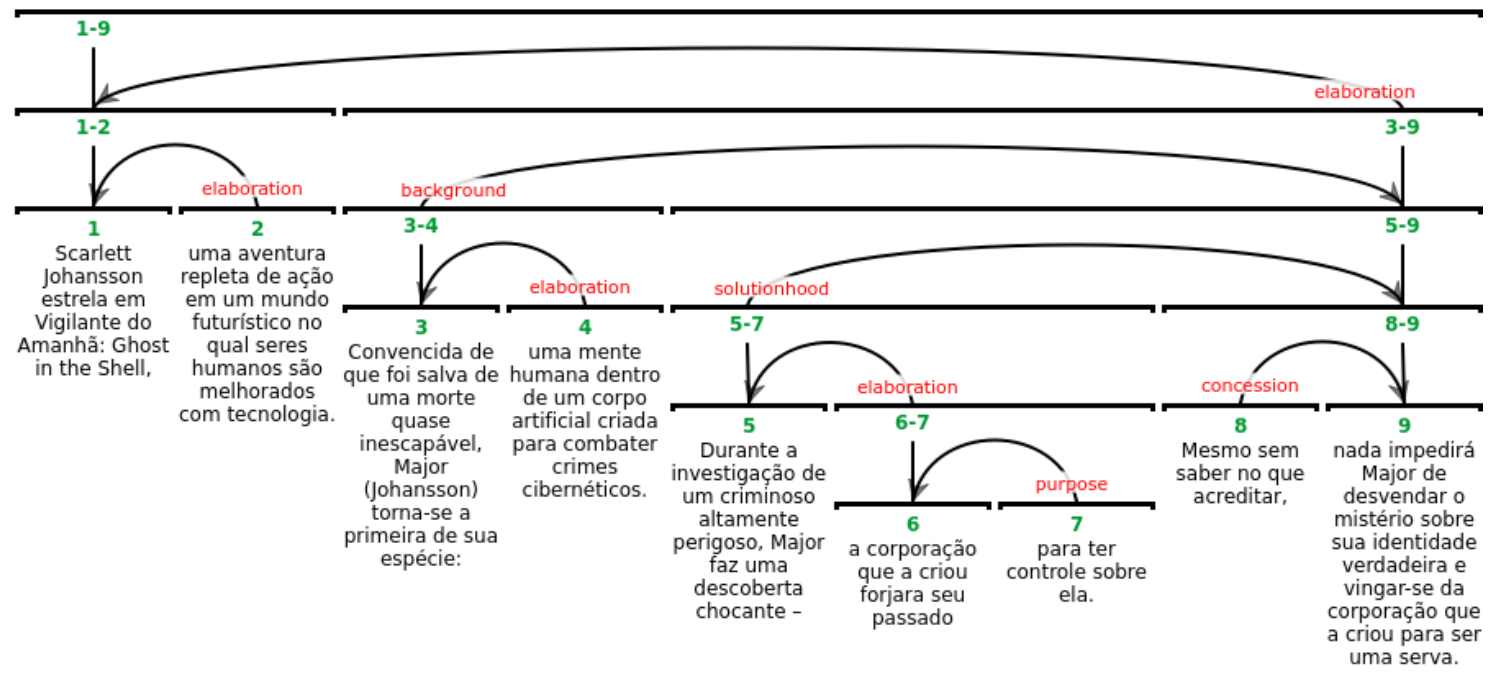

Figura 6 - Diagrama da estrutura retórica de uma sinopse traduzida (Fonte: os autores).

Em duas sinopses do córpus (Beauty and the beast - about the movie; La la land review), houve alteração em alguma relação sem que a mudança fosse motivada por diferenças na segmentação. No diagrama da figura 7, observa-se, na EDU 7, a relação "result", sinalizada por "e". No texto vertido para o português (diagrama da figura 8), o tradutor optou pela relação "purpose", sinalizada por "para”. As relações entre as informações são estabelecidas, assim, de forma diferente pelos tradutores, pois todo texto é "concebido como um ponto de partida em direção a um leque de possibilidades de interpretação" (BOITO; MARINS, 2017, p. 130).

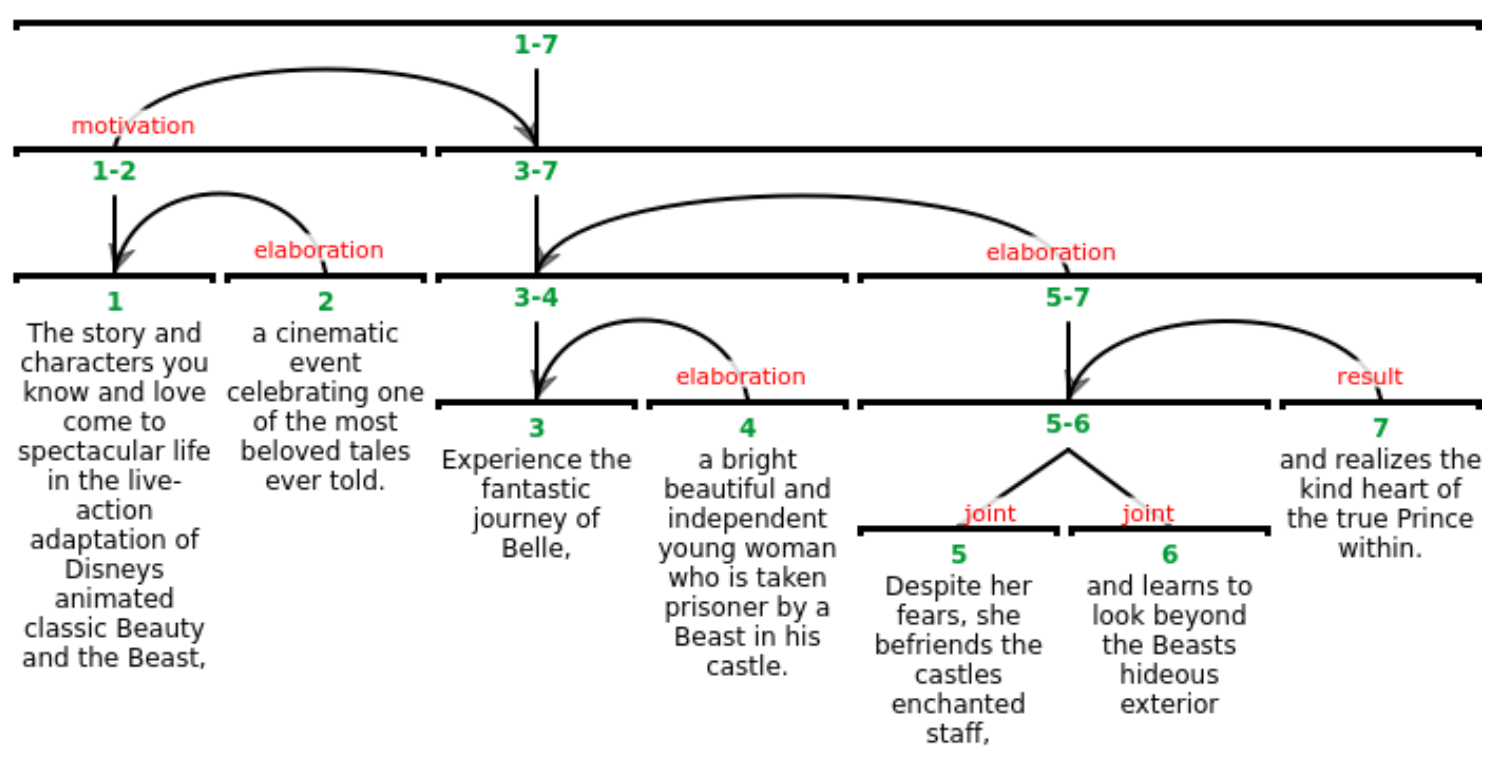

Figura 7 - Diagrama da estrutura retórica de uma sinopse-fonte (Fonte: os autores). 


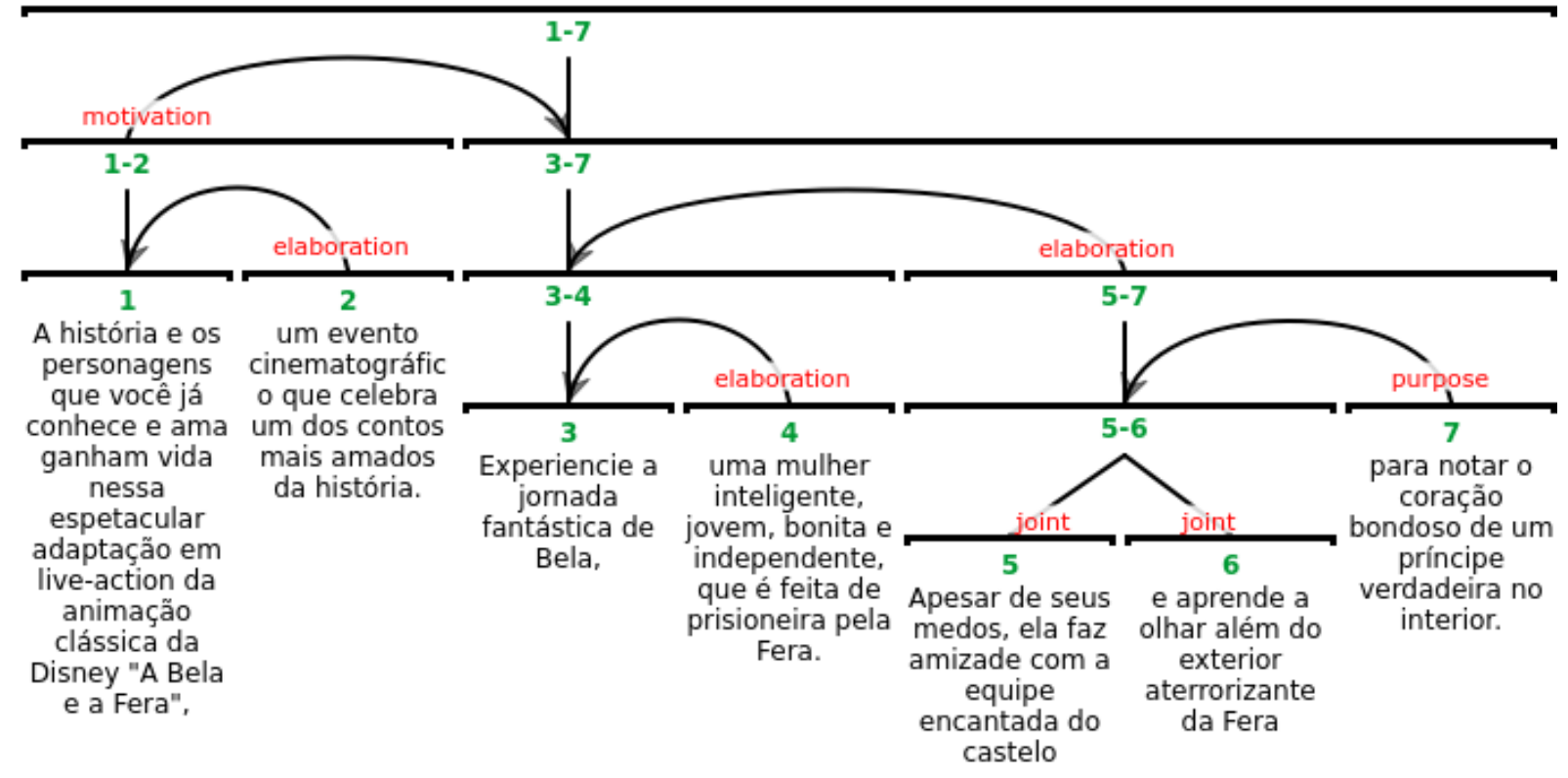

Figura 8 - Diagrama da estrutura retórica de uma sinopse traduzida (Fonte: os autores).

Dois tipos de inadequações foram observados nas tomadas de decisão dos tradutores (que podem ter sido causadas, inclusive, pela falta de revisão). Nas sinopses dos filmes The zookeeper's wife - about the motive, Colossal - about the movie e Colossal - review, houve problema de referência. No exemplo (05), retirado da sinopse do filme Colossal, o tradutor realizou uma retomada desnecessária com o pronome "ela" nas EDUs 3 e 4. Como as EDUs de 2 a 4 mantêm o mesmo tópico (Gloria), não há necessidade de retomá-lo pronominalmente. Esse tipo de retomada poderia ser considerado comum na língua falada coloquial. No entanto, em um texto escrito da natureza de uma sinopse, tal uso não é adequado. Outro problema pode ser encontrado na EDU 5, na qual o tradutor apresenta um referente novo ("gigante criatura") como se fosse informação dada. A sinalização de informação dada é feita por meio do demonstrativo "aquela”. É um uso inadequado porque se trata da primeira menção do referente "gigante criatura" no texto.

(05) 1 Gloria (Anne Hathaway) is an out-of-work party girl who,

2 after getting kicked out of her apartment by her boyfriend (Dan Stevens),

3 is forced to leave her life in New York City and move back to her hometown

4 where shes reunited with her childhood friend (Jason Sudeikis).

5 When news reports surface that a giant creature is destroying Seoul, South Korea, 6 Gloria comes to the realization that she is somehow connected to this far-off phenomenon. 
1 Gloria (Anne Hathaway) é uma garota festeira, sem trabalho,

2 que depois de ser despejada de seu apartamento pelo seu namorado (Dan Stevens), 3 ela é forçada a deixar sua vida em New York e voltar para sua casa, 4 onde ela se reune com seu amigo de infância (Jason Sudeikis).

5 Quando novos relatórios emergem que aquela gigante criatura está distruindo Seoul, South Korea,

6 Gloria chega a conclusão de que ela está de alguma forma ligada com esse fenômeno remoto.

A outra inadequação refere-se um truncamento sintático, encontrado na sinopse do filme Night of the living dead. Esse erro pode ser observado no exemplo (06), em que o tradutor mistura SNs das EDUs 2 e 3 do texto de partida. "Corpos reanimados" deveria ser sujeito da unidade 3, mas é utilizado na unidade 2 no lugar do SN "monstros de filmes”. No entanto, é importante ressaltar que a tradução, se considerada um processo empreendido por um sujeito que precisa lidar com diferentes escolhas tradutórias, com os mais diversificados gêneros, com uma variedade significativa de temas e com um tempo escasso de produção, está sujeita a incoerências e inadequações, como toda atividade humana.

(06) 2 Zombies had previously been relatively minor players in the pantheon of movie monsters,

3 reanimated corpses often seemed less scary than the likes of ghosts, vampires, and werewolves,

4 and were mostly the province of cheaply made drive-in flicks.

2 Os zumbis já haviam sido atores relativamente menores no panteão dos filmes de corpos reanimados

3 geralmente parecendo menos assustadores que fantasmas, vampiros e lobisomens, 4 e eram principalmente filmes baratos de cinemas drive-in.

No quadro 1 a seguir, sintetizam-se as estratégias utilizadas e os erros cometidos pelos tradutores. 


\begin{tabular}{|c|c|}
\hline Estratégias & Erros \\
\hline $\begin{array}{l}\text { 1. Reconstrução total de um período por meio } \\
\text { da mudança da posição de tópicos, alteração } \\
\text { da posição do adjetivo (predicativa ou atribu- } \\
\text { tiva), adição ou retirada de vocábulos; } \\
\text { 2. Acréscimo ou retirada do verbo em cons- } \\
\text { truções comparativas ou explicativas; } \\
\text { 3. Mudança do arranjo da combinação de ora- } \\
\text { ções por meio do uso de orações reduzidas de } \\
\text { gerúndio, utilização de construções paratáti- } \\
\text { cas ou hipotáticas em vez de orações subordi- } \\
\text { nadas e vice-versa; } \\
\text { 4. Mudança de classe de palavras: verbos são } \\
\text { nominalizados, formas participiais com fun- } \\
\text { ção de adjetivo são utilizadas no lugar de for- } \\
\text { mas verbais; } \\
\text { 5. Mudança de relação retórica motivada pela } \\
\text { troca do elemento linguístico que sinaliza a } \\
\text { relação. }\end{array}$ & $\begin{array}{l}\text { 1. Truncamento sintático, com a mistura entre } \\
\text { referentes que estavam no início de uma ora- } \\
\text { ção e os que estavam no final da oração ante- } \\
\text { rior; } \\
\text { 2. Retomada por meio de pronomes feita de } \\
\text { forma não adequada ao gênero sinopse; } \\
\text { 3. Apresentação de informação nova como se } \\
\text { fosse informação dada. }\end{array}$ \\
\hline
\end{tabular}

Quadro 1 - Sintetização das estratégias utilizadas e dos erros cometidos pelos tradutores Fonte: os autores.

\section{Considerações finais}

Este trabalho teve como objetivo investigar estratégias de segmentação e de tradução utilizadas por tradutores humanos. Realizou-se uma análise no nível da estrutura textual por meio da Rhetorical Structure Theory (RST) em um córpus formado por treze sinopses de filmes em inglês e suas versões do inglês para o português feitas por formandos do curso de Tradução. Investigou-se a frequência de concordância entre a segmentação dos textos em unidades discursivas elementares e compararam-se as estruturas retóricas dos textos-fonte e as estruturas retóricas das traduções.

Por meio da análise identificaram-se cinco diferentes estratégias utilizadas pelos tradutores e duas inadequações no processo de versão dos textos do inglês para o português. A primeira estratégia constitui-se na reconstrução total de um período por meio da mudança da posição de tópicos, alteração da posição do adjetivo (predicativa ou atributiva), adição ou retirada de vocábulos. A segunda estratégia consiste no acréscimo ou 
na retirada do verbo em construções comparativas ou explicativas. Nesse último caso, opta-se por um adjetivo ou por uma oração explicativa. A terceira estratégia é a mudança do arranjo da combinação de orações por meio do uso de orações reduzidas de gerúndio, utilização de construções paratáticas ou hipotáticas em vez de orações subordinadas e vice-versa. A mudança de classe de palavras é a quarta estratégia encontrada no córpus. Por meio dela, verbos são nominalizados, formas participiais com função de adjetivo são utilizadas no lugar de formas verbais. A mudança de relação retórica motivada pela troca do elemento linguístico que sinaliza a relação também é uma estratégia utilizada pelos tradutores. Nesse caso, a mudança na estrutura retórica não é motivada por alterações que afetam a segmentação dos textos, como ocorre nas estratégias mencionadas anteriormente.

No que diz respeito às inadequações, os problemas encontrados foram o truncamento sintático, com a mistura entre referentes que estavam no início de uma oração e os que estavam no final da oração anterior; a retomada por meio de pronomes feita de forma não adequada ao gênero sinopse; e a apresentação de informação nova como se fosse informação dada.

Os resultados mostram que os tradutores humanos, diferentemente dos tradutores mecânicos, promovem transformações inevitáveis nas estruturas linguísticas do texto traduzido, as quais são fruto da relação deste sujeito tanto com a língua estrangeira quanto com sua própria língua materna. Justamente por ser humana, ela se distancia de uma possível busca por equivalências estruturais entre línguas que são, a rigor, diferentes.

\section{Referências}

ARROJO, R. Os Estudos da Tradução Na Pós-Modernidade, O Reconhecimento da Diferença e A Perda da Inocência. Cadernos de Tradução, Florinópolis, v. 1, n.1, p. 53-70, 1996.

BOITO, F. S.; MARINS, L. C. Expansão interpretativa e tradução: pluralidade e descentrismo. PERcursos Linguísticos, Vitória, v.7, n. 16, p. 124-135, 2017.

CARLSON, L.; MARCU, D. Discourse Tagging Reference Manual. Los Angeles: University of Southern California, 2001.

CORACINI, M.J. R. F. O sujeito tradutor entre a "sua" língua e a língua do outro. Cadernos de Tradução, Florianópolis, v. XVI, p. 09-24, 2005.

COSTA, Maria José R. D.; ZILPSER, Maria Elisabeth; POLCHLOPEK, Silvana;. Tradução como ação comunicativa: a perspectiva do funcionalismo nos estudos da tradução. Revista Tradução \& Comunicação, n. 24, p 21-37, 2012.

DA CUNHA, I.; IRUSKIETA, M. Comparing rhetorical structures in different languages: the influence of translation strategies. Discourse Studies, v. 12, n. 5, p. 563-598, 2010. 
GENTZLER, E. Teorias contemporâneas da tradução. São Paulo: Madras, 2009.

MANN, William C; THOMPSON, Sandra A. Rhetorical Structure Theory: Toward a Functional Theory of Text Organization. Text, Sydney, v.8, n. 3, p. 243-281, 1998.

MATTHIESSEN, C. Remembering Bill Mann. Computational Linguistics, Cambridge, MA, v.31, n.2, p. 161-172, 2005.

NEVES, M. H. M. Gramática de Usos do Português. São Paulo: Ed. da Unesp, 2000.

RODRIGUES, C. C. Tradução e diferença. São Paulo: Ed. da Unesp, 2000.

STEDE, M. RST revisited: disentangling nuclearity. In: FABRICIUS-HANSEN, C.; RAMM, W. (orgs.); "Subordination" versus "coordination" in sentence and text. Amsterdam: John Benjamins, 2008. p. 33-57. 